\title{
Problems of continuing education of senior people
}

\section{E. A. Ermakova ${ }^{1}$}

${ }^{1}$ Bryansk State Technical University, 750 let Oktyabrya Boulevard, Bryansk 241035, Russian Federation

DOI: $10.18255 / 2412-6519-2020-4-358-367$

Research Article

Full text in Russian

The increase in life expectancy and the share of the elderly population are the main demographic trends in the world and Russia. They actualize the need to find ways to prevent and overcome the negative consequences for society of demographic aging of the population. One of them is the inclusion of representatives of the "third age" in the system of continuing education. Thanks to it, older people can easily adapt to the changes that are taking place in all areas of modern society. At the same time, inclusion in continuing education contributes not only to the continuation of the work of older people, but also creates conditions for maintaining the intellectual, aesthetic, moral and civic level provided by selfeducation or through institutionalized mechanisms of formal education.

This article summarizes the realized and the experience of foreign and Russian practices of teaching the elderly, studied the degree of their readiness to continue learning, analyzes issues and trends of continuing education representatives of the "third age», revealed the motives that drive them to continue to learn and barriers to formal and informal education.

Keywords: continuing education; older people; educational potential; third age; third age universities; ageism

\section{INFORMATION ABOUT THE AUTHORS}

\begin{tabular}{l|l} 
Ermakova, Ekaterina A. & E-mail: ermakova.20@mail.ru
\end{tabular} Assistant of the Department of Humanities and social disciplines, postgraduate student of The Federal research sociological center of the Russian Academy of Sciences

For citation: Ermakova E. A. Problems of continuing education of senior people // Social'nye i gumanitarnye znanija. 2029. Vol. 6, No 4. P. 358-367. (in Russ.) 


\section{Проблемы непрерывного образования пожилых людей}

\section{Е. А. Ермакова ${ }^{1}$}

1Брянский государственный технический университет, бульвар 50 лет Октября, 7, Брянск, 241035, Российская Федерация

DOI: $10.18255 / 2412-6519-2020-4-358-367$

УДК 316

Научная статья

Полный текст на русском языке

Увеличение продолжительности жизни и доли пожилого населения - главные демографические тенденции в мире и России. Они актуализируют необходимость поиска путей предупреждения и преодоления негативных последствий демографического старения населения для общества. Одним из таких путей является включение представителей «третьего возраста» в систему непрерывного образования. В постоянно меняющемся мире трудно переоценить значение и востребованность непрерывного образования. Благодаря ему пожилые люди могут беспроблемно адаптироваться к изменениям, которые происходят во всех сферах современного общества. В то же время включение в непрерывное образование не только способствует продолжению трудовой деятельности и улучшению качества жизни пожилых людей, но и создает условия для поддержания интеллектуального, эстетического, морального и гражданского уровня, обеспечиваемого за счет самообразования или посредством институционализированных механизмов формального образования.

В статье обобщен и осмыслен опыт зарубежных и российской практик обучения пожилых людей, изучена степень их готовности к продолжению обучения, проанализированы проблемы и тенденции непрерывного образования представителей «третьего возраста», выявлены мотивы, побуждающие их продолжать учиться, а также барьеры, препятствующие получению формального и неформального образования.

Ключевые слова: непрерывное образование; пожилые люди; образовательный потенциал; третий возраст; университеты третьего возраста; эйджизм

\section{ИНФОРМАЦИЯ ОБ АВТОРАХ}

Ермакова, Екатерина Александровна

Email: ermakova.20@mail.ru

Аспирант Института социологии ФГБУН Федеральный научно-исследовательский социологический центр

Российской академии наук

Для цитирования: Ермакова Е. А. Проблемы непрерывного образования пожилых людей // Социальные и гуманитарные знания. 2020. Том 6, № 4. С. 358-367.

(C) Ермакова Е. А., 2020

Статья открытого доступа под лицензией СС BY (https://creativecommons.org/licenses/by/4.0/) 


\section{Введение}

Увеличение продолжительности жизни и старение возрастной структуры населения - главная мировая демографическая тенденция, которая наблюдается и в России. Согласно данным Федеральной службы государственной статистики, к 2036 году доля пожилых людей увеличится с 25,4 \% от общей численности населения страны до 31,1 \% по высокому варианту прогноза или до 30,8 \% - по низкому варианту прогноза [1]. Данная тенденция рассматривается современными учеными как достижение человеческой цивилизации, связанное с улучшением социально-экономических условий жизнедеятельности людей.

По расчетам Минтруда РФ, на начало 2018 года насчитывалось 12,3 млн. работающих пенсионеров, т. е. каждый четвертый представитель старшей возрастной страты. В 2020 году предполагается рост доли работающих пенсионеров с 7,6 до 8,2 \% от числа всех работающих. По данным Сбербанка, в котором аккумулируются доходы большинства пенсионеров, к этому времени средний доход работающих пенсионеров составил 32 тысячи рублей, а с учетом пенсии - 46 тысяч рублей. Но к 75 годам, т. е. моменту перехода в категорию стариков, работающих остается 2 \%. Средний доход категории стариков - 14100 рублей.

Возрастающий интерес научного сообщества к изучению различных аспектов образования пожилых людей объясняется его потенциалом в качестве эффективного государственного инструмента для решения актуальных социальных проблем, вызванных демографическим старением. Представители пожилого возраста рассматриваются как носители человеческого капитала, готовые к постоянному обновлению своих знаний и навыков.

В России и во многих других странах существует понимание необходимости поддержания образовательного потенциала представителей «третьего возраста», который не только обеспечит им возможность продолжить трудовую деятельность, но и создаст условия поддержания интеллектуального, эстетического, морального и гражданского уровня жизни, обеспечиваемого за счет самообразования или посредством институализированных механизмов формального образования [2, с. 120].

Составляя социальный портрет пожилого населения в России, М. А. Варламова и О. В. Синявская пришли к выводу, что в «третий возраст» вступили намного более образованные поколения, пережившие опыт адаптации к новым социально-экономическим реалиям, они и идущие за ними поколения несут уже другой образ восприятия старости, иные представления о качестве и стиле жизни пожилых людей [3]. Современные пожилые люди образуют качественно иной социальный слой, для которого характерны повышенные требования к своему социальному статусу, условиям реализации прав и свобод, возможности непрерывно продолжать свое образование.

Г. Е. Зборовский и П. А. Амбарова отмечают, что образовательная деятельность представителей этой общности способна превратить ее из проблемной в ресурсную. Важная характеристика такой деятельности и ее назначение - стать нематериальным активом самых разных форм и видов профессионально-трудовой, интеллектуальной, культурно-досуговой, гражданской активности [4, с. 21].

Д. М. Рогозин, анализируя результаты проходившего в Ивановской области исследования отношения людей старшего возраста к обучению и труду, сделал вывод 
о том, что востребованность образования пожилым человеком, склонность к получению новых знаний существенным образом меняет его социальную позицию. Этот человек уже может рассматриваться не как доживающий свой век, получающий гарантированную пенсию и коротающий досуг, а в качестве проектировщика собственной судьбы, независимо от бытующих в социуме стигматов старшего возраста [5, с. 28].

Интеграция представителей «третьего возраста» в систему непрерывного образования является, по Н. В. мнению Бондаренко, ответом на актуальные вызовы современности. Такое образование предполагает повышение профессиональной квалификации, профессиональную переориентацию, обучение и переобучение трудовым навыкам. С его помощью пожилые люди могут беспроблемно адаптироваться к трансформациям, которые происходят во всех сферах современного общества [6].

Для понимания перспектив поддержания образовательного потенциала пожилых людей в России необходимо проанализировать отечественный и зарубежный опыт обучения представителей «третьего возраста», выявить проблемы и тенденции развития непрерывного образования старшего поколения, а также оценить потенциал использования образования пожилых для решения насущных социальных проблем.

\section{Сравнительный анализ систем образования пожилых людей за рубежом и в России}

В Европе в конце XX века включение пожилых людей в систему непрерывного образования было продиктовано не мировыми демографическими тенденциями, а необходимостью приведения их профессиональной квалификации в соответствие с ускоренными темпами роста производств и производственных технологий.

Первый университет для пожилых людей появился в 1973 году в Тулузе (Франция). Учебный процесс в университете организовывался на классических академических стандартах образования и шел параллельно с научными исследованиями, целью которых было выяснение способности представителей «третьего возраста» воспринимать и воспроизводить новую информацию.

В 1980-х гг. в Великобритании появилась добровольная ассоциация «Общество третьего возраста», где пожилые люди самостоятельно объединялись в образовательные группы и делились друг с другом своими профессиональными знаниями и практическими навыками [7]. Британская организация образовательного процесса отражала идеи И. Иллича, который выступал против институализации образования для пожилых. По его мнению, в процессе передачи знаний учителя уподобляются оракулам, а учащиеся теряют способность к самостоятельному критическому мышлению, поэтому образовательная система должна стать более гибкой и подвижной с тем, чтобы обеспечить доступ к образовательным ресурсам всем желающим, способствовать свободному обмену знаниями и создавать предпосылки для передачи профессиональных навыков [8]. Именно эти идеи стали основными для британских университетов третьего возраста.

В настоящее время во всем мире увеличивается число учебных заведений и образовательных программ, которые специализируются на обучении пожилых людей. Сейчас в Америке и Европе по программам университетов третьего возраста обучается более 2,2 млн. человек. Р. Манхаймер в своих исследованиях отмечает, что с каж- 
дым десятилетием все больше пожилых американцев участвуют в тех или иных видах формального и неформального обучения [9]. В азиатских странах насчитывается более 4,3 млн. учащихся старше 60 лет. В 2013 году наиболее успешными странами с точки зрения подготовки пожилых людей были скандинавские страны, Великобритания и Франция, Испания, Италия и Германия были ниже средних показателей по EC-28. Образовательный процесс в этих странах строится на сочетании организационных принципов классического французского и неклассического британского непрерывного образования. Так, например, в Финляндии университеты третьего возраста ориентируются на академические образовательные программы и вместе с тем используют опыт и знания самих пожилых учащихся. В Канаде представители третьего возраста учатся наравне с учащимися других возрастных групп и при наличии уних профильного образования в прошлом могут получить степень бакалавра. В США обучение в университетах третьего возраста проходит в формате «Elder hostel» (позже «Road Scholar»). Суть такого обучения заключается в сочетании путешествия и обучения. Пожилой человек, путешествуя по различным интересным местам, во время остановок слушает лекции, подготовленные сотрудниками вузов. В Южной Америке университеты третьего возраста существуют как центры социальной поддержки населения и ориентированы на представителей социальных низов. В КНР в образовании пожилых преобладает традиционный тип образования. У безработных пожилых людей шансов быть вовлеченными в учебную деятельность меньше, чем у работающих.

Б. Финдсен и М. Формоза отмечают, что особенность зарубежных образовательных программ состоит в их направленности на поддержание представителей третьего возраста как социальной группы, которая готова и способна воспроизводить знания и навыки, полученные в ходе непрерывного образования для решения не только профессиональных, но и жизненных задач [9].

В исследованиях зарубежных ученых, таких как Д. Дьюи [10], М. Ноулз [11], Э. Линдерман [12] и др., особое внимание уделяется изучению условий социальной активности и инклюзии представителей пожилого возраста посредством практик их вовлечения в различные виды образования. Т. М. Кононыгина отмечает, что задача обучения пожилых людей: «представлена зарубежными исследователями не только как процесс адаптации и компенсации потерь в связи с возрастными изменениями, а как особая образовательная культура, формирующая новый облик старости - продуктивной, компетентной, деятельной, наполненной жизненной энергией, опытом, мудростью пожилых» [13].

В России так же, как и в зарубежных странах, существует образовательная система для пожилых людей. Однако потребность в ней невысока: в образовательный процесс включено всего лишь 8 \% населения в возрасте 55-64 лет [14]. Д. М. Рогозин связывает низкий процент включенности пожилых людей с двумя основными факторами. Во-первых, с неготовностью существующих институтов образования к обучению представителей данной возрастной группы: недостаточной разработанностью специализированных образовательных программ, отсутствием специалистов в области геронтологического образования, ориентированных на специфику работы с немолодыми учениками. Во-вторых, с нежеланием самих пожилых людей к дальнейшему обучению [5]. Тем не менее в больших городах и в регионах постепенно увеличивается число учреждений, где пожилые люди могут продолжить свое образование. 
В России существует три направления образования пожилых людей: формальное, неформальное и информальное. Формальное образование подразумевает под собой получение новой профессии, повышение квалификации или переквалификацию. С выходом на пенсию представителей пожилого возраста обычно исключают из формального образования. Однако пожилой человек может стать студентом вуза и получить диплом бакалавра или магистра наравне с представителями молодого поколения. Работающие пенсионеры могут на общих основаниях пройти курсы повышения квалификации или курсы профессиональной переподготовки. На 2016 г. численность слушателей, завершивших обучение по дополнительным профессиональным программам в возрасте 60 лет и старше, составила 6,7 \% [14, с. 190].

Самой распространенной среди пожилых людей формой дополнительного образования является неформальное обучение. В отличие от формального образования, неформальное не имеет строгой нормативности, и представители пожилого возраста могут свободно обмениваться своими навыками, тем самым самостоятельно организуя образовательный процесс. Его реализуют через различные центры социального обслуживания населения, «народные школы», «народные университеты» или «университеты третьего возраста». В таких образовательных учреждениях пожилые люди изучают огромное количество программ, разнообразие которых увеличивается с каждым годом. Например, первоначально наиболее востребованными среди пожилых людей были компьютерные курсы, а теперь популярность набирают курсы английского языка, экономики, права, живописи, танцев, ландшафтного дизайна и др.

Информальное образование подразумевает под собой самообразование пожилых людей. Концепция информального образования дает возможность использовать в процессе обучения сочетание жизненного и профессионального опыта пожилых людей. Получение такого образования стало возможно благодаря развитию различных информационных площадок, целью которых является адаптация представителей третьего возраста к реалиям современного мира. Примером самообразования является занятие копирайтерством, в ходе которого пенсионеры на практике осваивают приемы маркетинга, журналистики, психологического консультирования $[15$, с. 148$]$.

Таким образом, непрерывное образование является необходимым инструментом для интеграции представителей старшего поколения в экономическую сферу общества. Для включения представителей предпенсионного и пенсионного возраста в профессиональное образование Правительством РФ и различными общественными организациями разрабатываются различные проекты, например, национальный проект «Демография», социальные проекты «Активная жизнь старшего поколения», «Школа активного долголетия», «Московское долголетие» и др. Однако не все регионы в равной степени способны обеспечить условия для реализации данных образовательных проектов, что способствует исключению значительной доли представителей пожилого возраста, сохранивших высокую остаточную трудоспособность, из экономической сферы общества.

\section{Методы}

В данной работе произведен вторичный анализ данных, полученных, во-первых, в ходе комплексного социологического исследования «Жизненные стратегии и социальные практики активного долголетия людей пожилого (третьего) возраста» 
(кабинетное исследование, массовый формализованный опрос 1500 респондентов, 4 фокус-группы, 20 экспертных интервью на территории Московской и Ивановской областей), проведенного под руководством И. П. Потехиной и Д. В. Чижова в регионах ЦФО в 2015 г. с целью изучения и анализа положительного опыта по созданию условий, способствующих повышению продолжительности и качества жизни, поддержанию социальной активности и работоспособности, формированию здорового образа жизни и активного долголетия пожилых людей [16], и, во-вторых, в результате Мониторинга экономики образования, который проводится НИУ ВШЭ ежегодно, начиная с 2002 года [17].

\section{Результаты}

Что заставляет пенсионеров продолжать свое образование? Можно выделить две группы мотивов: профессиональные и личные. По данным исследования РІААС (Международное исследование компетенций взрослого населения), основным мотивом участия в непрерывном образовании взрослых в странах ОЭСР (Организация экономического сотрудничества и развития) является потребность, связанная с работой [18]. Эти данные коррелируют с результатами мониторинга экономики образования, проведенного НИУ ВШЭ. Было установлено, что для 65 \% участвовавших в непрерывном образовании основными мотивами являются профессиональные интересы [17].

К профессиональным мотивам участия в непрерывном образовании можно отнести желание сохранить свое нынешнее рабочее место и достичь на нем успеха, совершенствовать знания и навыки (почти для $40 \%$ участвовавших в непрерывном образовании в 2016 г.), повысить профессиональную квалификацию в своей текущей профессиональной деятельности (для 14 \%) и, соответственно, заработать больше (для 13 \%) [17, с. 141]. Низкий уровень пенсии, по мнению экспертов, является основной причиной, по которой люди пожилого возраста продолжают свою трудовую деятельность, и лишь немногие работают в первую очередь для ощущения нужности обществу.

Личные мотивы участия в непрерывном образовании чаще всего связаны с личными интересами вне работы в качестве хобби, для организации своего досуга. Образование вносит существенный вклад в улучшение здоровья и повышает социальную, а также гражданскую активность пожилых людей.

В качестве основных причин неучастия в формальном и неформальном дополнительном образовании представителей третьего возраста выделяют несформированные потребности и отсутствие осознанной необходимости в дальнейшем обучении, а также эйджизм в отношении пожилых людей, существующий в российском обществе. Несмотря на то, что в российском законодательстве с 2019 г. предусмотрена уголовная ответственность за необоснованное увольнение или отказ в трудоустройстве пожилых людей из-за возраста, традиционно большинство работодателей отдает предпочтение более молодым соискателям на вакантные места. Увеличению риска быть уволенным и сокращению возможности найти новую работу способствуют такие факторы, как устаревшие знания и навыки пожилых людей, проблемы с адаптацией к новым технологиям, отсутствие стимулов к переобучению, ухудшение здоровья и дискриминация по возрасту [17, С. 167-172].

В ходе научного исследования реального экономического потенциала представителей третьего возраста, проводившегося под руководством И. П. Потехиной и Д. В. Чижова, были выявлены сильные и слабые стороны представителей третьего возраста на рынке 
труда. К сильным сторонам они отнесли такие качества, как высокий уровень компетентности в своей профессиональной области, дисциплинированность и ответственность. К слабым сторонам были отнесены ухудшение здоровья, морально-психологические сложности, которые возникают у руководителей, в подчинении которых находятся рабочие более старшего возраста [16, с. 14].

Кроме этого, социологи обнаружили три альтернативные модели поведения пожилых после выхода на пенсию, показывающие их разные жизненные установки и ожидания:

1) дожитие, характеризующееся спадом активности во всех сферах, повышенным вниманием лишь к здоровью и текущим бытовым и семейным проблемам (39\%);

2) переориентация на другие сферы, характеризующаяся переключением на общественно полезную деятельность, реализацию себя в социальной, общественно-политической или семейной сфере (37\%);

3) продолжение активного образа жизни, характеризующееся сохранением установок на трудовую деятельность (24\%). Сохранить или найти работу, которая бы соответствовала социальному статусу и знаниям, пожилым людям удавалось лишь в том случае, если работа была связана с уникальными компетенциями или узкой специализацией, востребованной и на сегодняшний день. Но чаще пожилые люди занимали вакансии, наименее привлекательные для других категорий населения, работая на низкоквалифицированных рабочих специальностях, не требующих дополнительного образования [19].

Доминирование отрицательного отношения пожилых к продолжению трудовой деятельности после выхода на пенсию обусловлено комплексом объективных и субъективных факторов:

- ухудшением состояния здоровья, не позволяющим полноценно трудиться на большинстве рабочих мест;

- низкой востребованностью на рынке труда из-за профессиональной некомпетентности в сфере современных автоматизированных производств;

- отсутствием адекватных предложений на рынке труда, которые могли бы сочетать в себе возможности самореализации и достойного заработка;

- дискриминацией по возрасту со стороны работодателей;

- падением профессионального статуса после выхода на пенсию.

Однако по отношению к дополнительному обучению было выявлено противоречие между высокой степенью способности это делать и низким уровнем готовности и желания учиться. 69 \% респондентов отмечают свою способность приобретать новые знания и умения. Противоположной позиции придерживаются 22 \%. В то же время 68 \% пожилых не готовы этим заниматься. Лишь 23 \% респондентов утвердительно ответили на этот вопрос, а 7 \% уже занимаются на курсах обучения и самообразования [16, с. 16].

Основная проблема обучения представителей пожилого возраста заключается в том, что образовательные курсы, которые связаны с хобби или направлены на расширение коммуникационных возможностей, являются более предпочтительными, чем курсы, имеющие профессиональную направленность. Исследователи предположили, что ключевым фактором отказа от дополнительного образования стало непонимание респондентами сферы его применения.

Образование пожилых людей способно решить проблему социальной адаптации пенсионеров. Специальные программы формального и неформального дополнительного образования направлены на обучение различным навыкам, которые необходимы в повседневной жизни, благоприятно влияют на здоровье, а также 
оказывают воздействие на адаптивные способности представителей третьего возраста, создают благоприятные условия принятия пожилыми людьми социальных изменений, процесса старения и состояния старости.

\section{Заключение}

В современных условиях положение пожилых людей усложняется во всех сферах общественной жизни. Образование является базой для дальнейшего благополучия, улучшения качества жизни, поэтому особую важность приобретает готовность пожилых людей к обучению на протяжении всей жизни.

Несмотря на то, что количество образовательных учреждений увеличивается с каждым годом, качество предоставляемых ими услуг ставится под сомнение. Деятельность таких учреждений не имеет должной организованности, необходимой методической и кадровой оснащенности. Поэтому главным вектором в развитии непрерывного образования пожилых людей является развитие образовательной среды, специализированных образовательных учреждений - «университетов третьего возраста», которые будут соответствовать современными общественным тенденциям и будут ориентированы на дальнейшую адаптацию людей старшего возраста.

В массовом сознании и молодого, и старшего поколения старость ассоциируется с периодом исключения стариков из образовательного пространства как не поддающихся обучению, имеющих дефицит времени для ответных компенсаторных действий, но не имеющих никакой социальной цели, кроме работы по дому и воспитания внуков. Это свидетельствует о доминировании в обществе эйджизма. Под влиянием общественных негативных стереотипов у представителей пожилого возраста формируется представление о себе как «неперспективной» и «бесполезной» для общества категории людей, которой учиться ни к чему.

Работодатели обычно считают, что пожилые работники имеют меньший учебный потенциал, хотя разрыв в успеваемости с молодыми работниками может быть уменьшен с помощью различных образовательных мероприятий, которые соответствуют потребностям обучения пожилых работников. Кроме того, хотя работники старшего возраста реже покидают свои рабочие места, чем работники молодого возраста, работодатели считают, что они имеют меньший срок службы, и поэтому рассматривают обучение пожилых работников как инвестицию с более низкой прибылью. Нежелание руководителей вкладывать средства в обучение пожилых работников - это более серьезное препятствие на пути развития непрерывного образования пожилых, нежели их личное нежелание получать выгоду от обучения. Отсутствие профориентационных мероприятий приводит к тому, что дальнейшее получение образования не наделяется социально полезным смыслом. Это приводит к обесцениванию образования и дальнейшего развития представителей третьего возраста.

\section{Ссылки / References}

1. Уточненный демографический прогноз до 2036 года // Росстат. 28.12.2019. URL: https://www.gks.ru/folder/313/document/72529 (дата обращения: 01.04.2020).

2. Касьянова Т. И., Воронина Л. И., Резер Т. М. Образовательный потенциал российских граждан пожилого возраста // Образование и наука. 2020. Т. 22. № 2. С. 120-141. DOI:10.17853/1994-5639-2020-2120-141. 
3. Варламова М. А., Синявская О. В. Портрет пожилого населения России // Демоскоп Weekly. 2015. № 627-628. URL: http://www.demoscope.ru/weekly/2015/0627/tema08.php (дата обращения: 03.03.2020).

4. Зборовский Г. Е., Амбарова П. А. Роль образования в сохранении и развитии социальной общности людей «третьего возраста» // Вестник Пермского национального исследовательского политехнического университета. Социально-экономические науки. 2019. № 2. C. 21-34. DOI: 10.15593/2224-9354/2019.2.2

5. Рогозин Д. М. Либерализация старения, или труд, знания и здоровье в старшем возрасте // Старикам тут место: социальное осмысление старения: [сборник научных статей] / Институт социологии РАН; отв. ред. Д. М. Рогозин, А. А. Ипатова. М.: Институт социологии PAH, 2016. С. 8-41.

6. Бондаренко Н. В. Становление в России непрерывного образования: анализ на основе результатов общероссийских опросов взрослого населения страны // Мониторинг экономики образования. Информационный бюллетень. М.: НИУ ВШЭ, 2017. № 5 (104). 28 с.

7. Formosa M. Four decades of Universities of the third age: Past, present and future // Ageing a. society. Cambridge, 2014. Vol. 34. P. 42-66.

8. Иллич И. Освобождение от школ. Пропорциональность и современный мир. (Фрагменты из работ разных лет): [пер. с нем., англ.]. М.: Просвещение, 2006. 149 с.

9. International perspectives on older adult education / Ed. by B. Findsen, M. Formosa. Cham: Springer, 2016. Vol. XIX. 519 p.

10. Dewey J. The School and Society. Chicago: University of Chicago Press, 1900. URL: https://ia801408.us.archive.org/33/items/schoolsociety00dewerich/schoolsociety00dewerich_ bw.pdf . (дата обращения: 03.03.2020).

11. Knowles M. S., Holton III E. E., Swanson R. A. The Adult Learner: The Definitive Classic in Adult Education and Human Resource Development. 6th ed. London, N.Y.: ELSEVIER Butterworth Heinemann, 2005. 416 p.

12. Lindeman E. C. The Meaning of Adult Education. N.Y.: New Republic, 1926. 224 p.

13. Кононыгина Т. М. Герагогика. Пособие для тех, кто занимается образованием пожилых людей. Орел: Красная строка, 2006.148 с.

14. Индикаторы образования: 2018: статистический сборник / Н. В. Бондаренко, Л. М. Гохберг, Н. В. Ковалева и др. Нац. исслед. ун-т «Высшая школа экономики». М.: НИУ ВШЭ, 2018. 400 c.

15. Королева Е. Г., Мухлаева Т. В. Образование для пожилых в контексте концепции «благополучного старения» // Человек и образование. 2018. № 4. С. 147-151.

16. Потехина И. П., Чижов Д. В. Потенциал старшего поколения как составляющая национального человеческого капитала (по материалам исследования в регионах ЦФО) // Мониторинг общественного мнения: Экономические и социальные перемены. 2016. № 2. C. 3-23.

17. Век живи - век учись: непрерывное образование в России / И. А. Коршунов, О. С. Гапонова, В. М. Пешкова; под ред. И. Д. Фрумина, И. А. Коршунова // Нац. исслед. ун-т «Высшая школа экономики», Ин-т образования. М.: Изд. дом Высшей школы экономики, 2019. 310 с.

18. Desjardins R. Participation in adult education opportunities: Evidence from PIAAC and policy trends in selected countries. Background paper prepared for the Education for All Global Monitoring Report 2015 // Education for All 2000-2015: achievements and challenges. URL: http://unesdoc.unesco.org/images/0023/002323/232396e.pdf (дата обращения: 03.03.2020).

19. Ключарев Г. А. Век учись - век живи // Социологические исследования. 2019. № 8. С. 167172. DOI: $10.31857 /$ S013216250006182-33. 